\title{
FUNÇÃO SOCIOAMBIENTAL DA PROPRIEDADE: A busca por uma determinação pragmática de aferição de cumprimento
}

\section{ENVIRONMENTAL FUNCTION OF PROPERTY: The search for a pragmatic determination for measuring compliance}

\section{Daniela Oliveira Gonçalves ${ }^{1}$ Elcio Nacur Rezende ${ }^{2}$}

\begin{abstract}
RESUMO: Atualmente muito se discute acerca da função socioambiental da propriedade, cujo cumprimento representa uma condicionante ao direito de propriedade. O presente estudo pretende analisar os requisitos legais para o cumprimento da função socioambiental da propriedade rural, buscando uma determinação pragmática de aferição de cumprimento, permitindo assim uma avaliação objetiva da propriedade.
\end{abstract}

PALAVRAS-CHAVE: Propriedade. Função socioambiental. Requisitos.

ABSTRACT: Currently there is much discussion about the environmental function of property, compliance with which is a constraint to the right of ownership. This study aims to examine the legal requirements for compliance with the environmental function of land ownership, seeking a pragmatic determination for measuring compliance, thus allowing an objective assessment of the property.

KEYWORDS: Property. Environmental function. Requirements.

\section{INTRODUÇÃO}

A preservação do meio ambiente sempre teve grande importância para a manutenção da vida em todas as suas formas, porém a preocupação com a preservação ambiental e a discussão acerca da forma de utilização dos recursos naturais é relativamente recente nas sociedades. Já o direito à propriedade sempre ocupou lugar de destaque nas legislações, constituindo a base dos direitos patrimoniais. Ao longo do tempo o direito de propriedade foi se adaptando ás mudanças sociais, e passou a sofrer algumas limitações, em busca do bem social. Atualmente, a propriedade permanece como um direito individual, mas que deve ser exercido em harmonia com os interesses sociais.

\footnotetext{
${ }^{1}$ Mestranda em Direito Ambiental e Desenvolvimento Sustentável na Escola Superior Dom Helder Câ- mara. Especialista em Direito e Processo do Trabalho pela PUCMINAS. Graduada em Direito pela Universidade Salgado de Oliveira (2010) e e graduada em Matemática pela Universidade Federal de Minas Gerais (1999). Atualmente é professora da FACSAL - Faculdade de Santa Luzia. Experiência na área de Direito, com ênfase em Direito do Trabalho. E-mail: daniog71@yahoo.com

${ }^{2}$ Mestre e Doutor em Direito. Coordenador e Professor do Programa de PósGraduação em Direito da Escola Superior Dom Helder Câmara.E-mail: elcio@domhelder.edu.br
} 
Revista da Faculdade de Direito-RFD-UERJ- Rio de Janeiro, n. 28, dez. 2015

As limitações ao direito de propriedade visam retirar o caráter absoluto e individualista do instituto, que deve ser exercido não apenas em benefício do seu titular, mas também de toda a coletividade. Tais limitações foram implantadas na medida em que os valores sociais evoluíram e atualmente a propriedade deve cumprir sua função socioambiental, ou seja, deve ser exercida em obediência a aspectos econômicos, sociais e ambientais. Ressalta-se que as questões ambientais têm ganhado importância, em especial após a Constituição federal de 1988 e representam atualmente um aspecto essencial para a sociedade.

O presente trabalho apresenta um breve histórico da evolução no conceito de propriedade e função social, para em seguida apresentar o conceito de função socioambiental. Num segundo momento, serão apresentados os requisitos para cumprimento da função socioambiental nas propriedades rurais, buscando uma abordagem pragmática para aferição de seu cumprimento.

\section{O DIREITO DE PROPRIEDADE E A FUNÇÃO SOCIAL}

A propriedade representa o poder que uma pessoa exerce sobre um bem. $\mathrm{O}$ direito à propriedade existe desde os mais remotos tempos, nas mais variadas organizações sociais. Nas palavras de Nelson Rosenvald e Cristiano Chaves 3 , "a história da propriedade é a história da liberdade". Para estes autores, a propriedade é uma instituição natural, presente em todas as sociedades. Para Caio Mário da Silva ${ }^{4}$, a propriedade é fenômeno espontâneo, decorrente da necessidade de subsistência do ser humano, sendo posteriormente regulado a fim de possibilitar a convivência social pacífica.

Ao longo do tempo, o conceito de propriedade sofreu várias alterações, numa tentativa de acompanhar as evoluções sociais. Dessa forma, no transcurso da história a propriedade exerceu várias funções, evoluindo da propriedade absoluta e individualista até a propriedade limitada pela função socioambiental dos dias atuais.

Em geral, nas sociedades mais primitivas prevalecia o sentimento de coletividade, pois os homens viviam em tribos e os bens pertenciam a todos. Apenas em relação a bens móveis se verificava a propriedade privada.

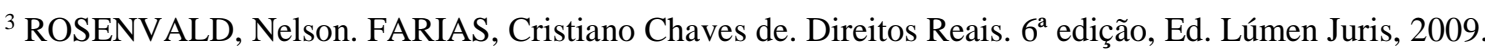

${ }^{4}$ PEREIRA, Caio Mário da Silva. Instituições de Direito Civil. Volume III. Rio de Janeiro: Forense. 2003
} 
$\mathrm{Na}$ Antiguidade, os homens passaram a se fixar na terra, fazendo surgir a idéia de propriedade. Inicialmente a propriedade era carregada de conceitos sagrados, que faziam com que fosse vista como um direito absoluto e inalienável. Segundo Fustel de Coulanges ${ }^{5}$, a propriedade privada não existiu em todas as civilizações e algumas delas só a admitiram depois de muito tempo. Para o autor, na antiguidade o conceito de propriedade privada se ligava à religiosidade, que dava à família a propriedade da casa, do túmulo de adoração e de um pequeno espaço para cultivo. Nessa época, a propriedade era uma coisa sagrada, conforme se verifica do seguinte trecho da obra Cidade Antiga:

\begin{abstract}
"Há três coisas que desde as mais antigas eras, encontram-se fundadas e solidamente estabelecidas nas sociedades grega e italiana: a religião doméstica, a família e o direito de propriedade; três coisas que tiveram entre si, na origem, uma relação evidente, e que parecem terem sido inseparáveis. A idéia de propriedade privada estava implícita na própria religião. Cada família tinha seu lar e seus antepassados. Esses deuses não podiam ser adorados senão por ela, e não protegiam senão a ela; eram sua propriedade exclusiva."
\end{abstract}

$\mathrm{Na}$ sociedade romana o direito de propriedade evoluiu ao longo do tempo. Segundo Aloísio Surgik ${ }^{6}$, a propriedade privada em Roma se restringia, inicialmente, à propriedade familiar, constituída pela casa, o campo em torno dela a sepultura familiar. A propriedade não se concentrava no indivíduo, mas sim no grupo familiar, sendo exercida de forma absoluta. Não havia exatamente um conceito de propriedade, mas sim a definição de seus atributos: ius utendi, ius fruendi e ius abutendi. (usar, gozar e dispor).

Com o tempo, o território romano foi dividido em função de sua utilização. Havia áreas próprias para lavouras, pastos, bosques de uso comum, etc. A propriedade possuía funcionalidade, ou seja, era exercida em prol do interesse social. Segundo Maria Cristina Pezella $^{7}$, citada por Nelson Rosenvald, é clara a submissão do exercício do direito de propriedade ao interesse social. De acordo com a autora,

\footnotetext{
“a submissão do exercício da propriedade à sociedade toda evidencia o privilégio do princípio da humanidade sobre os demais princípios do direito, o que permite que se afaste também o individualismo como característica da propriedade romana, pois mesmo quando exercida individualmente, a propriedade romana sempre esteve sujeita ao interesse social"
}

\footnotetext{
${ }^{5}$ COULANGES, Fustel. A cidade Antiga [e-book] eBooks Brasil. 2006

${ }^{6}$ SURGIK, Aloísio. A luta pela propriedade da terra na história de Roma e no Brasil - considerações críticas. , in Revista da Faculdade de Direito da UFPR

${ }^{7}$ ROSENVALD, Nelson. FARIAS, Cristiano Chaves de. Direitos Reais. 6a edição, Ed. Lúmen Juris, 2009
} 
No período feudal, na Idade Média, verifica-se a fragmentação do poder político. O território era dividido em vários feudos, cada um pertencente a um senhor feudal, que detinha poder absoluto sobre a terra. A propriedade da terra concedia ao senhor feudal um poder soberano sobre os vassalos, que recebiam o direito de explorar uma parcela da terra em troca do pagamento de renda. A propriedade era exercida de maneira absoluta, visando apenas interesses privados dos senhores feudais. Aos servos restava apenas a posse da terra. Nessa época a sociedade se dividia entre o clero, a nobreza e os servos e apenas os primeiros tinham a propriedade da terra.

Nesse período a Igreja Católica detinha grande poder e propagava a moral cristã. Assumindo o papel de defensora da humanidade e dos interesses sociais, trouxe à discussão a semente do conceito de função social da propriedade, através principalmente do pensamento de Santo Agostinho e São Tomas de Aquino. Para Aquino, "é melhor ter a propriedade privada, mas fazer o uso dela comum". 8

Com as Cruzadas o sistema feudal entra em crise, pois o isolamento dos feudos se rompe e o comércio renasce. Com isso, os burgos ou centros urbanos se desenvolvem, surgindo uma nova classe social, formada pelos comerciantes e chamada de burguesia, que foi aos poucos, tirando o poder dos senhores feudais. Surge o êxodo rural, pois os servos deixam os feudos e se dirigem aos centros urbanos em busca de oportunidades de trabalho.

Com o fortalecimento da burguesia, as idéias iluministas ganham destaque e alteram o formato do direito de propriedade. O homem é agora um ser livre e racional que pode realizar seus interesses. Com a Revolução Francesa o conceito de propriedade retoma sua origem romana. A propriedade passa a ser o direito de gozar e dispor das coisas de maneira absoluta. Surge a propriedade como direito individual e absoluto, sem qualquer preocupação com a função social. Busca-se assegurar direitos subjetivos ao indivíduo em face do Estado, conforme se verifica no artigo 17 da Declaração dos Direitos do Homem e do Cidadão: "Como a propriedade é um direito inviolável e sagrado, ninguém dela pode ser privado, a não ser quando a necessidade pública legalmente comprovada o exigir e sob condição de justa e prévia indenização". De acordo com Guilherme José Purvin", é a “consagração de uma

\footnotetext{
${ }^{8}$ MOTA, Maurício. Fundamentos Teóricos da Função Social da propriedade: a propriedade em Tomás de Aquino. Revista Aquinate, n. 9. 2009

${ }^{9}$ FIGUEIREDO, Guilherme José Purvin de. A propriedade no Direito Ambiental. 4 ed. Ver., atual. E ampl. São Paulo: Editora Revista dos Tribunais, 2010
} 
Revista da Faculdade de Direito-RFD-UERJ- Rio de Janeiro, n. 28, dez. 2015

concepção individualista da propriedade privada". Ainda segundo o autor, "o liberalismo apregoará que o Estado deve limitar-se a ser garantidor das relações estabelecidas pelos particulares, promovendo a proteção da vida, da segurança individual das pessoas e da propriedade"

Com o passar do tempo, a propriedade privada absoluta sofre restrições com o objetivo de garantir direitos sociais. $\mathrm{O}$ direito à propriedade permanece, mas seu exercício passa a ser limitado. Nas palavras de Nelson Nones ${ }^{10}$, "essa nova concepção do direito de propriedade envolveu posicionamentos de filósofos e juristas europeus de diversas tendências, entre os quais, Marx, Engels, Comte, Duguit e vários precursores do socialismo, que objetivavam desconstituir o conceito absolutista - inviolável e sagrado - do direito de propriedade."

O conceito de função social da propriedade é apresentado por Leon Duguit ${ }^{11}$, no final do século XIX. Para o autor:

\begin{abstract}
"todo individuo tiene la obligación de cumplir em la sociedad uma cierta función em razón directa del lugar que em ella ocupa. Ahora bien, el possedor de la riqueza, por lo mismo que posee la riqueza, puede realizar um cierto trabajo que solo el puede realizar. Sólo el puede aumentar la riqueza general haciendo valer el capital que posee. Está, pues, obligado socialmente a realizar esta tarea, y no será protegido socialmente más que si la cumple y em la medida que la cumpla. La propriedad no es, pues, El derecho subjetivo del proprietário; es la función social del tenedor de la riqueza"
\end{abstract}

Para Duguit, os indivíduos têm deveres sociais, devendo utilizar sua riqueza em prol dos interesses de toda a sociedade. Com base nessa visão é que surge a idéia de função social da propriedade. Segundo Purvin ${ }^{12}$,

\begin{abstract}
"A teoria de Duguit parte da concepção do Direito como resultado constante e espontâneo dos fatos, e não como mera obra do legislador. Assim, ainda que leis e códigos permaneçam intactos, as necessidades surgidas na vida em sociedade acabam por formar constantemente novas instituições jurídicas. Foi a necessidade de superar as concepções individualistas do Direito Privado, nas quais o homem é tomado isoladamente - destacado de seus semelhantes -, que resultou na consagração da noção de função social da propriedade."
\end{abstract}

Ainda segundo Nones ${ }^{13}$,

\footnotetext{
${ }^{10}$ NONES, Nelson. Direito de propriedade e função social: evolução histórico-jurídica. Revista Jurídica CCJ/FURB

${ }^{11}$ DUGUIT, Leon, Las transformaciones Del derecho. Buenos Ayres apud FAZIO, Federico Leandro de. La

"filosofia positiva", El derecho y lãs relaciones laborales em Argentina a principio del siglo XX. Revista de Estudos Jurídicos, n. 22, 2011.

${ }^{12}$ FIGUEIREDO, Guilherme José Purvin de. A propriedade no Direito Ambiental. 4 ed. Ver., atual. E ampl. São

Paulo: Editora Revista dos Tribunais, 2010.

${ }^{13}$ NONES, Nelson. Direito de propriedade e função social: evolução histórico-jurídica. Revista Jurídica $\mathrm{CCJ} / \mathrm{FURB}$
} 
"Duguit (1923, p. 295) defendeu a idéia de que só o detentor da riqueza poderia cumprir a tarefa social de aumentar a riqueza geral e, por isso, o proprietário era socialmente obrigado a desempenhar essa função e só seria protegido se a executasse, e na medida e limites em que deveria cumpri-la".

A partir de Duguit, a solidariedade social foi evoluindo e atualmente representa um dos pilares do direito. As legislações passaram a incluir normas relativas à função social da propriedade, estabelecendo limites ao exercício do direito de propriedade com o objetivo de compatibilizar o direito individual com os interesses sociais. Assim, o proprietário possui o dever de dar à propriedade uma destinação, sob pena de ser responsabilizado.

Atualmente exige-se não apenas o cumprimento da função social da propriedade, mas também o cumprimento da função sócio-ambiental.

\section{FUNÇÃO SOCIOAMBIENTAL NA LEGISLAÇÃO BRASILEIRA}

A legislação ambiental foi, aos poucos, evoluindo. Antes mesmo da atual Constituição Federal, já em 1964, com a promulgação do Estatuto da Terra (Lei no 4.504/64), o princípio da função social da propriedade foi inserido na legislação brasileira, de forma ampla, condicionando a propriedade ao cumprimento de exigências relacionadas com a produtividade, direito trabalhistas, conservação do meio ambiente e bem estar dos proprietários e trabalhadores, conforme determina o art. $2^{\circ}$ da norma:

\footnotetext{
Art. $2^{\circ}$. É assegurada a todos a oportunidade de acesso à propriedade da terra, condicionada pela sua função social, na forma prevista nesta Lei.

$\S 1^{\circ}$ A propriedade da terra desempenha integralmente a sua função social quando, simultaneamente:

a) favorece o bem-estar dos proprietários e dos trabalhadores que nela labutam, assim como de suas famílias;

b) mantém níveis satisfatórios de produtividade;

c) assegura a conservação dos recursos naturais;

d) observa as disposições legais que regulam as justas relações de trabalho entre os que a possuem e a cultivam.
}

A função social da propriedade foi constitucionalizada pela primeira vez na Carta de 1967, no ar. 157, como um princípio da ordem econômica e social. A Constituição Federal de 1988 incluiu a função social da propriedade no rol de direitos e garantias individuais (art. $5^{\circ}$, XXIII) e a manteve como princípio da ordem econômica (art. 170, III). Além disso incluiu um capítulo específico para o Meio Ambiente, no art. 225. o direito ambiental ganhou status 
Revista da Faculdade de Direito-RFD-UERJ- Rio de Janeiro, n. 28, dez. 2015

de direito fundamental difuso, e como tal, recebeu proteção, devendo ser preservado para as presentes e futuras gerações:

Art. 225. Todos têm direito ao meio ambiente ecologicamente equilibrado, bem de uso comum do povo e essencial à sadia qualidade de vida, impondo-se ao Poder Público e à coletividade o dever de defendê-lo e preservá-lo para as presentes e futuras gerações.

Mas a norma constitucional foi além e ampliou o conceito de função social do art. 186, ao incluir em seus elementos caracterizadores, aspectos ambientais e trabalhistas além do aproveitamento adequado:

\footnotetext{
Art.186. A função social é cumprida quando a propriedade rural atende, simultaneamente, segundo critérios e graus de exigência estabelecidos em lei, aos seguintes requisitos:

I - aproveitamento racional e adequado;

II - utilização adequada dos recursos naturais disponíveis e preservação do meio ambiente;

III - observância dos disposições que regulam as relações de trabalho;

IV - exploração que favoreça o bem-estar dos proprietários e dos trabalhadores.
}

Dessa forma, mais uma limitação à propriedade foi imposta. Além da exigência de cumprimento da função social, o meio ambiente também deve ser protegido pelo proprietário. Tal exigência é conhecida por função socioambiental da propriedade.

Também o Código Civil de 2002 apresenta a função socioambiental, de forma indireta, em especial nos parágrafos primeiro e segundo do art. 1228:

\footnotetext{
Art. 1.228. O proprietário tem a faculdade de usar, gozar e dispor da coisa, e o direito de reavê-la do poder de quem quer que injustamente a possua ou detenha.

$\S 1 .^{\circ} \mathrm{O}$ direito de propriedade deve ser exercido em consonância com suas finalidades econômicas e sociais e de modo que sejam preservados, de conformidade com o estabelecido em lei especial, a flora, a fauna, as belezas naturais, o equilíbrio ecológico e o patrimônio histórico e artístico, bem como evitada a poluição do ar e das águas.

$\S 2 .^{\circ}$ : São defesos os atos que não trazem ao proprietário qualquer comodidade, ou utilidade, e sejam animados pela intenção de prejudicar outrem.
}

Outras leis ordinárias também prevêem a função socioambiental da propriedade. O Estatuto da Terra (Lei n ${ }^{\circ} 4.504 / 64$ ), além da previsão do art. $2^{\circ}$, já citada, traz em seu artigo 12 que "à propriedade privada da terra cabe intrinsecamente uma função social; seu uso é condicionado ao bem-estar coletivo". A lei no 10.257 de 2001, estabelece no parágrafo único do art. $1^{\circ}$ que o Estatuto da Cidade "estabelece normas de ordem pública e interesse social que regulam o uso da propriedade urbana em prol do bem coletivo, da segurança e do bem-estar dos cidadãos, bem como do equilíbrio ambiental”. 
A legislação brasileira prevê ainda, nas hipóteses de descumprimento da função sócio ambiental, sanções para os proprietários. De acordo com o art. 184 da Constituição Federal, as propriedades que não cumprirem sua função social podem ser desapropriadas para fins de reforma agrária, mediante indenização em títulos da dívida agrária. Os infratores também se sujeitam a sanções penais, administrativas e civis previstas em várias leis ambientais (multas, obrigação de indenizar, demolição de obra, obrigação de reparar o dano, dentre outras).

\section{A FUNÇÃO SOCIOAMBIENTAL DA PROPRIEDADE RURAL}

A função socioambiental da propriedade possui ainda mais relevância na área rural, onde a distribuição da terra normalmente se apresenta de forma desigual. É comum a existência de grandes propriedades, muitas vezes sem qualquer forma de destinação ou até mesmo causando grande degradação. Essa forma desigual de distribuição da terra, além de ser causa de vários conflitos agrários, por muitas vezes é também a causa de danos ambientais.

O descumprimento da função socioambiental da propriedade dá ao Poder Público o direito de desapropriação para reforma agrária, conforme previsto no art. 184 da Constituição Federal:

\footnotetext{
Art. 184. Compete à União desapropriar por interesse social, para fins de reforma agrária, o imóvel rural que não esteja cumprindo sua função social, mediante prévia e justa indenização em títulos da dívida agrária, com cláusula de preservação do valor real, resgatáveis no prazo de até vinte anos, a partir do segundo ano de sua emissão, e cuja utilização será definida em lei.
}

Pela previsão constitucional, para desapropriar é necessário comprovar que a propriedade rural não cumpre a função socioambiental.

Quando se trata especificamente de área rural, a propriedade deve cumprir todas as exigências do Estatuto da Terra e da Constituição Federal. Para que a propriedade cumpra sua função socioambiental não basta que sejam impostas limitações ao exercício do direito de propriedade. Ao proprietário também são impostas obrigações positivas, tais como realizar exploração de forma sustentável, afastar danos ambientais, implantar áreas de preservação permanente, dentre outras.

A Lei 8.629/93 regulamenta os dispositivos constitucionais relativos à reforma agrária para propriedades rurais que não cumprirem sua função social. A competência para 
Revista da Faculdade de Direito-RFD-UERJ- Rio de Janeiro, n. 28, dez. 2015

desapropriação é da União, que a realiza através do Instituto Nacional de Colonização e Reforma Agrária - INCRA, autarquia federal responsável pela aferição do cumprimento da função socioambiental da propriedade rural.

O INCRA deve realizar o levantamento de dados e informações do imóvel, de acordo com as determinações legais. A propriedade ou imóvel rural está definida no art. $4^{\circ}$ da referida lei como "o prédio rústico de área contínua, qualquer que seja a sua localização, que se destine ou possa se destinar à exploração agrícola, pecuária, extrativa vegetal, florestal ou agro-industrial". Verifica-se aqui que prevalece a Teoria da Destinação, segundo a qual, de acordo com o Ministro Dias Toffoli, em acórdão de 12/09/2011, na Reclamação 2326/RJ, “A definição de imóvel rural, em sede de desapropriação para fins de reforma agrária, é aferida pela sua destinação, não interessando que esteja localizado em zona urbana.

A função socioambiental da propriedade rural é cumprida quando atendidos os critérios do art. 184 da Constituição Federal, que foram repetidos no art. $9^{\circ}$ da Lei $\mathrm{n}^{\circ}$ 8.629/93:

Art. $9^{\circ}$ A função social é cumprida quando a propriedade rural atende, simultaneamente, segundo graus e critérios estabelecidos nesta lei, os seguintes requisitos:

I - aproveitamento racional e adequado;

II - utilização adequada dos recursos naturais disponíveis e preservação do meio ambiente;

III - observância das disposições que regulam as relações de trabalho;

IV - exploração que favoreça o bem-estar dos proprietários e dos trabalhadores.

$\S 1^{\circ}$ Considera-se racional e adequado o aproveitamento que atinja os graus de utilização da terra e de eficiência na exploração especificados nos $\S \S 1^{\circ}$ a $7^{\circ}$ do art. $6^{\circ}$ desta lei.

$\S 2^{\circ}$ Considera-se adequada a utilização dos recursos naturais disponíveis quando a exploração se faz respeitando a vocação natural da terra, de modo a manter o potencial produtivo da propriedade.

$\S 3^{\circ}$ Considera-se preservação do meio ambiente a manutenção das características próprias do meio natural e da qualidade dos recursos ambientais, na medida adequada à manutenção do equilíbrio ecológico da propriedade e da saúde e qualidade de vida das comunidades vizinhas.

$\S 4^{\circ}$ A observância das disposições que regulam as relações de trabalho implica tanto o respeito às leis trabalhistas e aos contratos coletivos de trabalho, como às disposições que disciplinam os contratos de arrendamento e parceria rurais.

$\S 5^{\circ}$ A exploração que favorece o bem-estar dos proprietários e trabalhadores rurais é a que objetiva o atendimento das necessidades básicas dos que trabalham a terra, observa as normas de segurança do trabalho e não provoca conflitos e tensões sociais no imóvel. 
Revista da Faculdade de Direito-RFD-UERJ- Rio de Janeiro, n. 28, dez. 2015

Segundo Valdez Adriani Farias ${ }^{14}$, Procurador Federal de Santa Catarina, por muito tempo o INCRA considerava, em seus relatórios apenas os percentuais de GUT - Grau de Utilização da Terra - e GEE - Grau de Eficiência da Exploração, deixando de lados os demais requisitos legais. Assim, propriedades que degradavam o meio ambiente, não contribuíam para o bem estar dos trabalhadores e descumpriam legislação trabalhista não eram desapropriadas. Com o objetivo de dar efetividade ao art. $9^{\circ}$ da Lei $n^{\circ} 8.629 / 93$, em todos os seus aspectos, o Ministério do Desenvolvimento Agrário elaborou o Parecer Conjunto/CPALNP--CGAPJP/CJ/MDA/nº $011 / 2004$, que se tornou vinculante para o INCRA, determinando que apenas não serão desapropriadas as propriedades que cumprirem todos os requisitos elencados na lei.

Dessa forma, não há mais dúvida de que a propriedade rural, para cumprir sua função socioambiental, deve cumprir todos os requisitos legais, sob pena de desapropriação. O problema atual está na aferição de cumprimento dos requisitos, que exige uma análise complexa e multidisciplinar.

A lei determina a aferição de vários requisitos, relativos à aproveitamento, uso e preservação do meio ambiente, normas trabalhistas e bem estar de proprietários e trabalhadores, conforme determina o art. $9^{\circ}$ da Lei $n^{\circ} 8.629 / 93$, supracitado. Verifica-se que não existe um critério objetivo. A aferição do cumprimento da função socioambiental é uma tarefa complexa, que exige uma análise complexa e multidisciplinar.

No tocante à produtividade, a verificação deve ser baseada na interpretação dos arts. $6^{\circ}, 9^{\circ}$ e 10 da Lei $n^{\circ} 8.629 / 93$ além dos anexos que integram a Instrução Normativa $n^{\circ} 11$ do INCRA.

$\mathrm{O}$ art. $6^{\circ}$ determina que a propriedade deve cumprir, simultaneamente, um nível de utilização da terra e um nível de eficiência conforme índices definidos pelo INCRA. Para essa aferição, será necessário o levantamento da área total e da área utilizada da propriedade, além do cálculo de índices de eficiência na exploração:

Art. $6^{\circ}$ Considera-se propriedade produtiva aquela que, explorada econômica e racionalmente, atinge, simultaneamente, graus de utilização da terra e de eficiência na exploração, segundo índices fixados pelo órgão federal competente.

\footnotetext{
${ }^{14}$ Brasil. Instituto Nacional de Colonização e Reforma Agrária. Procuradoria Federal especializada junto ao INCRA. Lei 8629/93 comentada por procuradores federais: uma contribuição da PFE/INCRA para o fortalecimento da reforma agrária e do direito agrário autônomo
} 
$\S 1^{\circ} \mathrm{O}$ grau de utilização da terra, para efeito do caput deste artigo, deverá ser igual ou superior a $80 \%$ (oitenta por cento), calculado pela relação percentual entre a área efetivamente utilizada e a área aproveitável total do imóvel.

$\S 2^{\circ} \mathrm{O}$ grau de eficiência na exploração da terra deverá ser igual ou superior a $100 \%$ (cem por cento), e será obtido de acordo com a seguinte sistemática:

I - para os produtos vegetais, divide-se a quantidade colhida de cada produto pelos respectivos índices de rendimento estabelecidos pelo órgão competente do Poder Executivo, para cada Microrregião Homogênea;

II - para a exploração pecuária, divide-se o número total de Unidades Animais (UA) do rebanho, pelo índice de lotação estabelecido pelo órgão competente do Poder Executivo, para cada Microrregião Homogênea;

III - a soma dos resultados obtidos na forma dos incisos I e II deste artigo, dividida pela área efetivamente utilizada e multiplicada por 100 (cem), determina o grau de eficiência na exploração.

$\S 3^{\circ}$ Considera-se efetivamente utilizadas:

I - as áreas plantadas com produtos vegetais;

II - as áreas de pastagens nativas e plantadas, observado o índice de lotação por zona de pecuária, fixado pelo Poder Executivo;

III - as áreas de exploração extrativa vegetal ou florestal, observados os índices de rendimento estabelecidos pelo órgão competente do Poder Executivo, para cada Microrregião Homogênea, e a legislação ambiental;

IV - as áreas de exploração de florestas nativas, de acordo com plano de exploração e nas condições estabelecidas pelo órgão federal competente;

$\mathrm{V}$ - as áreas sob processos técnicos de formação ou recuperação de pastagens ou de culturas permanentes, tecnicamente conduzidas e devidamente comprovadas, mediante documentação e Anotação de Responsabilidade Técnica.

$\S 4^{\circ}$ No caso de consórcio ou intercalação de culturas, considera-se efetivamente utilizada a área total do consórcio ou intercalação.

$\S 5^{\circ}$ No caso de mais de um cultivo no ano, com um ou mais produtos, no mesmo espaço, considera-se efetivamente utilizada a maior área usada no ano considerado.

$\S 6^{\circ}$ Para os produtos que não tenham índices de rendimentos fixados, adotarse-á a área utilizada com esses produtos, com resultado do cálculo previsto no inciso I do $\S 2^{\circ}$ deste artigo.

$\S 7^{\circ}$ Não perderá a qualificação de propriedade produtiva o imóvel que, por razões de força maior, caso fortuito ou de renovação de pastagens tecnicamente conduzida, devidamente comprovados pelo órgão competente, deixar de apresentar, no ano respectivo, os graus de eficiência na exploração, exigidos para a espécie.

$\S 8^{\circ}$ São garantidos os incentivos fiscais referentes ao Imposto Territorial Rural relacionados com os graus de utilização e de eficiência na exploração, conforme o disposto no art. 49 da Lei no 4.504, de 30 de novembro de 1964.

Se os índices de GUT e GEE estiverem de acordo com as normas, será ainda necessário verificar se a produção foi racional, uma vez que a expressão legal da Lei 8.629/93 em seu art. $6^{\circ}$ é "explorada econômica e racionalmente" e no art. $9^{\circ}$ é "aproveitamento adequado e racional".

Para Josely Aparecida Trevisan Massuquetto ${ }^{15}$ :

15 Brasil. Instituto Nacional de Colonização e Reforma Agrária. Procuradoria Federal especializada junto ao INCRA. Lei 8629/93 comentada por procuradores federais: uma contribuição da PFE/INCRA para o fortalecimento da reforma agrária e do direito agrário autônomo. 
A exploração que se pretenda econômica e racional, deve primar, na administração dos diferentes recursos que o imóvel rural apresenta, pela funcionalidade, pela praticidade e pela racionalidade: a funcionalidade diz respeito à função típica da terra; sua atividade essencial; sua utilidade e serventia (produção de alimentos). A praticidade relaciona-se a uma ação ou conjunto de ações voltadas para a realidade do imóvel rural, em respeito à sua potencialidade e vocação. Por sua vez, a racionalidade envolve a adoção de técnicas e procedimentos que, de forma eficiente, torne o processo de produção menos dispendioso.

O aproveitamento racional não se afasta dos demais requisitos legais, que são: utilização adequada dos recursos naturais, observância das normas trabalhistas e favorecimento do bem estar dos proprietários e trabalhadores. Não há que se falar em aproveitamento racional quando há degradação ambiental ou desrespeito às normas trabalhistas. Dessa forma, como bem observa Joaquim Modesto Pinto Júnior ${ }^{16}$ :

\begin{abstract}
“(...) o art. $6^{\circ}$ da Lei $n^{\circ} 8.629 / 93$ considera propriedade produtiva aquela que é, explorada econômica e racionalmente. Quer dizer, a exploração econômica (produtividade) deve ser alcançada racionalmente. A contrário sensu, a exploração econômica (produtividade) alcançada de forma irracional, não será considerada para efeitos de cumprimento de uma das condicionantes da função social.

(...) os dispositivos estabelecem uma relação de indissociável complementaridade entre os conceitos de aproveitamento racional (adequado - art. $9^{\circ}, \S 1^{\circ}$ ), identificado plenamente com o inciso I do art. 186 da CF (produtividade), e o de exploração racional (art. $6^{\circ}$, caput) que projeta para dentro do aproveitamento os demais incisos do art. 186 da CF. Ora, ao passo que o aproveitamento racional está expressamente referido a GUT E GEE (produtividade, resultado), operando instrumentalmente para a consecução desses índices, a exploração racional é posta na lei como condição pra a validação desses índices."
\end{abstract}

Além de estarem contidos na expressão "racional", os demais requisitos da função socioambiental devem ser verificados. O segundo requisito legal trata do meio ambiente. Tratando-se de propriedade rural, é evidente a relação direta com o meio ambiente. A lei exige aqui o cumprimento de duas condições: a utilização adequada dos recursos naturais e a preservação do meio ambiente. $\mathrm{O} \S 2^{\circ}$ do art. $9^{\circ}$ da Lei 8.629/93 determina ainda que seja respeitada a vocação natural da terra. A utilização adequada dos recursos naturais visa manter a capacidade de proteção da terra, garantindo que os recursos não serão exauridos, enquanto a preservação ambiental envolve conceitos e exigências presentes em outras normas ambientais, tais como Áreas e Preservação Permanente, Reserva Legal e Unidades de Conservação, que impõem obrigações aos proprietários. Respeitar a vocação natural da terra, de acordo com a lei, é produzir de forma a manter o potencial produtivo da propriedade.

16 PINTO JÚNIOR, Joaquim Modesto, FARIAS, Valdez Adriani. Função Social da propriedade: dimensões ambiental e trabalhista. Brasília: Núcleo de Estudos Agrários e desenvolvimento Rural, 2005 
Área de preservação Permanente - APP e Reserva Legal estão previstas na Lei $\mathrm{n}^{\circ}$ 12.651/2012, que instituiu o novo Código Florestal, nos arts. $3^{\circ}, 4^{\circ}, 7^{\circ}$ e 12 , nos seguintes termos:

Art. 3 Para os efeitos desta Lei, entende-se por:

I - Amazônia Legal: os Estados do Acre, Pará, Amazonas, Roraima, Rondônia, Amapá e Mato Grosso e as regiões situadas ao norte do paralelo $13^{\circ} \mathrm{S}$, dos Estados de Tocantins e Goiás, e ao oeste do meridiano de $44^{\circ} \mathrm{W}$, do Estado do Maranhão; II - Área de Preservação Permanente - APP: área protegida, coberta ou não por vegetação nativa, com a função ambiental de preservar os recursos hídricos, a paisagem, a estabilidade geológica e a biodiversidade, facilitar o fluxo gênico de fauna e flora, proteger o solo e assegurar o bem-estar das populações humanas;

III - Reserva Legal: área localizada no interior de uma propriedade ou posse rural, delimitada nos termos do art. 12, com a função de assegurar o uso econômico de modo sustentável dos recursos naturais do imóvel rural, auxiliar a conservação e a reabilitação dos processos ecológicos e promover a conservação da biodiversidade, bem como o abrigo e a proteção de fauna silvestre e da flora nativa;

Art. 4ํ Considera-se Área de Preservação Permanente, em zonas rurais ou urbanas, para os efeitos desta Lei:

I - as faixas marginais de qualquer curso d'água natural perene e intermitente, excluídos os efêmeros, desde a borda da calha do leito regular, em largura mínima de:

a) 30 (trinta) metros, para os cursos d'água de menos de 10 (dez) metros de largura;

b) 50 (cinquenta) metros, para os cursos d'água que tenham de 10 (dez) a 50 (cinquenta) metros de largura;

c) 100 (cem) metros, para os cursos d'água que tenham de 50 (cinquenta) a 200 (duzentos) metros de largura;

d) 200 (duzentos) metros, para os cursos d'água que tenham de 200 (duzentos) a 600 (seiscentos) metros de largura;

e) 500 (quinhentos) metros, para os cursos d'água que tenham largura superior a 600 (seiscentos) metros;

II - as áreas no entorno dos lagos e lagoas naturais, em faixa com largura mínima de: a) 100 (cem) metros, em zonas rurais, exceto para o corpo d'água com até 20 (vinte) hectares de superfície, cuja faixa marginal será de 50 (cinquenta) metros;

b) 30 (trinta) metros, em zonas urbanas;

III - as áreas no entorno dos reservatórios d'água artificiais, decorrentes de barramento ou represamento de cursos d'água naturais, na faixa definida na licença ambiental do empreendimento;

IV - as áreas no entorno das nascentes e dos olhos d'água perenes, qualquer que seja sua situação topográfica, no raio mínimo de 50 (cinquenta) metros;

$\mathrm{V}$ - as encostas ou partes destas com declividade superior a $45^{\circ}$, equivalente a $100 \%$ (cem por cento) na linha de maior declive;

VI - as restingas, como fixadoras de dunas ou estabilizadoras de mangues;

VII - os manguezais, em toda a sua extensão;

VIII - as bordas dos tabuleiros ou chapadas, até a linha de ruptura do relevo, em faixa nunca inferior a 100 (cem) metros em projeções horizontais;

IX - no topo de morros, montes, montanhas e serras, com altura mínima de 100 (cem) metros e inclinação média maior que $25^{\circ}$, as áreas delimitadas a partir da curva de nível correspondente a $2 / 3$ (dois terços) da altura mínima da elevação sempre em relação à base, sendo esta definida pelo plano horizontal determinado por planície ou espelho d'água adjacente ou, nos relevos ondulados, pela cota do ponto de sela mais próximo da elevação;

$\mathrm{X}$ - as áreas em altitude superior a 1.800 (mil e oitocentos) metros, qualquer que seja a vegetação; 
XI - em veredas, a faixa marginal, em projeção horizontal, com largura mínima de 50 (cinquenta) metros, a partir do espaço permanentemente brejoso e encharcado.

Art. 7ำ A vegetação situada em Área de Preservação Permanente deverá ser mantida pelo proprietário da área, possuidor ou ocupante a qualquer título, pessoa física ou jurídica, de direito público ou privado.

Art. 12. Todo imóvel rural deve manter área com cobertura de vegetação nativa, a título de Reserva Legal, sem prejuízo da aplicação das normas sobre as Áreas de Preservação Permanente, observados os seguintes percentuais mínimos em relação à área do imóvel, excetuados os casos previstos no art. 68 desta Lei:

I - localizado na Amazônia Legal:

a) $80 \%$ (oitenta por cento), no imóvel situado em área de florestas;

b) $35 \%$ (trinta e cinco por cento), no imóvel situado em área de cerrado;

c) $20 \%$ (vinte por cento), no imóvel situado em área de campos gerais;

II - localizado nas demais regiões do País: $20 \%$ (vinte por cento).

O terceiro requisito a ser cumprido pela propriedade diz respeito às normas trabalhistas. As relações de trabalho existentes na propriedade devem respeitar todas as normas trabalhistas previstas no art. $7^{\circ}$ da Constituição Federal e nas demais normas trabalhistas. Dessa forma, devem ser avaliados não apenas os contratos de emprego, mas também os contratos de parceria, empreitadas e outros contratos de trabalho. Também deve ser verificada a existência de trabalho escravo ou condições análogas à escravidão.

Por fim, o quarto requisito se relaciona com o bem estar dos proprietários e dos trabalhadores. De acordo com Bruno Rodrigues Arruda e Silva ${ }^{17}$, Procurador Federal, tal requisito

“é apontado por nós como a função bem-estar, conceituada na lei como sendo a exploração que objetiva o atendimento das necessidades básicas dos que trabalham a terra, que observa as normas de segurança do trabalho e não provoca conflitos e tensões sociais no imóvel

(...)

A função bem-estar busca que o direito de propriedade seja exercido de forma harmônica entre proprietários e trabalhadores. É o vetor que direciona o exercício da propriedade com foco no desenvolvimento da sociedade, e não somente de seu titular. Reflete o primado da promoção do bem-estar e da justiça social, objetivos da ordem social traçados no art. 193 da CF/88".

Esse último requisito trás exigências abertas, com forte subjetivismo, o que pode dificultar a análise do órgão responsável e criar dificuldades para a efetivação das normas.

Reunindo as exigências legais, para determinar se uma propriedade rural é produtiva, é preciso:

\footnotetext{
${ }^{17}$ Brasil. Instituto Nacional de Colonização e Reforma Agrária. Procuradoria Federal especializada junto ao INCRA. Lei 8629/93 comentada por procuradores federais: uma contribuição da PFE/INCRA para o fortalecimento da reforma agrária e do direito agrário autônomo
} 
1) determinar o GUT (grau de utilização da terra) que se obtém com a aplicação da seguinte fórmula: $\mathrm{GUT}=\left(\frac{\text { årea efetivamente utilizada }}{\text { área aproveitåvel total }}\right) \times 100$

a) a determinação da área aproveitável da propriedade é realizada de forma residual. Da área total da propriedade, devem ser subtraídas as áreas não aproveitáveis, previstas no art. 10 da Lei $n^{\circ} 8.629 / 93$ e do art. $6^{\circ}$ da IN n ${ }^{\circ} 11$ do INCRA, como por exemplo, as ocupadas por construções e instalações, as áreas sob efetiva exploração mineral, as áreas especialmente protegidas por lei, etc.

b) a área efetivamente utilizada é obtida nos moldes do $\S 3^{\circ}$ do art. $6^{\circ}$ da Lei ${ }^{\circ}$ $8.629 / 93$ e do $\S 1^{\circ}$ do art. $5^{\circ}$ da IN $n^{\circ} 11$ do INCRA, devendo ser consideradas, por exemplo, as áreas plantadas, as áreas de exploração florestal nativa e outras. Se o imóvel for utilizado para pecuária, devem ser utilizadas outras tabelas que levam em consideração a Zona de pecuária do município, o $n^{\circ}$ de unidades animais - UA e o índice de lotação mínimo. Além disso, deve ser considerado que, independentemente do índice de rendimento mínimo por hectare, será considerada efetivamente utilizada a área coberta com floresta nativa cujo Plano de Manejo seja aprovado pelo órgão ambiental competente.

2) Determinar o GEE (grau de eficiência da exploração), através da aplicação da seguinte fórmula: $\mathrm{GEE}=\left(\frac{\text { inciso } \mathrm{I}+\text { inciso II }}{\text { area efetivamente utilizadal }}\right) \times 100$

a) para o cálculo do inciso I, que se refere a produtos vegetais, deve-se dividir a produção verificada pelos índices de rendimento oficiais (fixados pelo INCRA e disponíveis nos anexos da IN n ${ }^{\circ} 11$ do INCRA);

b) se a propriedade tiver exploração pecuária, o inciso II será calculado pela divisão do número total de unidades animais pelos índices de lotação oficial (também fixados pelo INCRA e disponíveis nos anexos da IN $\mathrm{n}^{\mathrm{o}} 11$ do INCRA);

3) Verificar se a produção foi racional, o que implica em uma análise subjetiva acerca da forma de produção em relação às características da propriedade (localização, tipo de terreno, meio ambiente, trabalhadores, etc.) 
4) Verificar se a utilização dos recursos naturais se deu de forma adequada e se o meio ambiente foi preservado. Aqui deve ser verificado o respeito à vocação natural da terra, a garantia de perenidade dos recursos e o cumprimento de todas as normas ambientais relativas às Áreas de Preservação Permanente, Reserva Legal e Unidades de Conservação, que impõem obrigações aos proprietários.

5) Aferir o cumprimento das normas trabalhistas, tanto nos contratos de emprego quanto nos contratos de parceria, empreitadas e outros contratos de trabalho.

6) Por fim, deve ser verificado se a propriedade proporciona bem estar aos proprietários e trabalhadores. Também aqui exige uma análise subjetiva, que deve observar se o direito à propriedade é exercido não apenas em benefício do proprietário.

Considerando que a função socioambiental da propriedade somente estará cumprida se todos os requisitos estivem simultaneamente obedecidos, até mesmo terras produtivas estarão sujeitas à desapropriação para fins de reforma agrária. O grande problema que se apresenta é a amplitude da norma. Para a verificação do cumprimento das exigências é necessário uma análise complexa e multidisciplinar das propriedades, uma vez que as exigências se relacionam com várias áreas de conhecimento. Para a verificação dos requisitos será necessário avaliar condições relativas à produtividade, com a utilização de vários índices agrários e tabelas específicas, que deveriam ser periodicamente atualizados, além de questões ambientais, que também requerem o conhecimento de normas e conceitos da área. Ademais, ainda são necessários conhecimentos na seara trabalhista, além de uma análise acerca do bemestar dos proprietários e trabalhadores, o que envolve uma análise subjetiva.

De maneira geral, o que se verifica na prática é um número reduzido de desapropriações decorrentes do descumprimento da função socioambiental da propriedade. Dentre as decisões favoráveis à desapropriação, a grande maioria é baseada apenas na improdutividade. Os demais requisitos legais praticamente não são utilizados pelos julgadores.

\section{UMA CRÍTICA SOBRE A AFERIÇÃO DO CUMPRIMENTO DA FUNÇÃO SOCIOAMBIENTAL A PARTIR DE CRITÉRIOS PRAGMÁTICOS}

Tentou-se nesse trabalho a aferição do cumprimento da função socioambiental baseada em critérios pragmáticos, ou seja, através da análise de aspectos práticos das normas 
ambientais, buscando uma forma objetiva de verificar se a propriedade cumpre os requisitos legais.

Considerando que existem vários conflitos por terra nas áreas rurais, que existem muitas propriedades que não cumprem sua função socioambiental e que a degradação ambiental já atingiu índices elevados, a adoção de medidas preventivas e compensatórias é uma necessidade urgente. Numa análise superficial, poder-se-ia afirmar que a exigência de critérios pragmáticos facilitaria a fiscalização, o que poderia colaborar para a efetividade das normas protetivas não apenas do meio ambiente, mas de outros direitos sociais.

Diante de um ritmo frenético de exploração dos recursos naturais, é compreensível que se abandonem as convicções morais e as normas abstratas. O que se busca, muitas vezes, é uma solução imediata para os problemas existentes.

O pragmatismo consiste numa forma de interpretação do direito que busca analisar os fatos e as normas de forma "realista", buscando efeitos práticos ou pragmáticos. Dessa forma, ao vistoriar uma propriedade rural, o representante do INCRA deve aplicar a norma à realidade, de forma prática, baseada nos fatos verificados e dessa forma determinar se a propriedade cumpre ou não sua função socioambiental.

Segundo Marcel Moraes Mota ${ }^{18}$,

Caracteriza-se o julgamento pragmático, tal como concebido por Posner, por seu viés empiricista, refratário a considerações abstratas de cunho moral ou de teoria política. Fundamentalmente, o juiz, seguindo-se essa linha de pensamento, deve-se ater aos fatos, ao conhecimento científico disponível, deixando de lado questões de filosofia moral, já que nenhuma formulação teórica abstrata teria utilidade para guiar o processo decisório. Em vez do recurso a teorias abstratas tidas por inservíveis, o julgador deve considerar a argumentação prática ordinária, ou do dia-a-dia, como sugere a idéia de everyday pragmatism.

O maior problema verificado na abordagem pragmática dos critérios para aferição do cumprimento da função socioambiental reside no fato que de o meio ambiente, assim como a sociedade, não se apresentam como fatos estáticos e imutáveis. Ao contrário, se apresentam como um conjunto de variáveis, das mais diversas espécies, que estão em constante mudança e evolução. Dessa forma, não basta a criação de índices matemáticos de verificação de produtividade ou a definição precisa de várias espécies de áreas de proteção ambiental. A adoção do pragmatismo pode resultar numa análise parcial das questões, pois segundo Dworkin $^{19}$,

O pragmatismo exige que juízes pensem de modo instrumental sobre as melhores regras para o futuro. Esse exercício pode pedir a interpretação de alguma coisa que

18 MOTA, Marcel Moraes. Posner, Kelsen e Hayek: Pragmatismo Jurídico, Positivismo Normativista e Liberalismo Político-Econômico Austríaco

${ }^{19}$ DWORKIN, Ronald. O império do direito. 2007 
extrapola a matéria jurídica: um pragmático utilitarista talvez precise preocupar-se com a melhor maneira de entender a idéia de bem-estar comunitário, por exemplo. Uma vez mais, porem, um juiz que aceite o pragmatismo não mais poderá interpretar a prática jurídica em sua totalidade."

Inegável que o pragmatismo é necessário em várias situações. Não há como tornar efetivas normas ambientais sem que se tomem decisões práticas e utilitárias, com vistas no alcance de resultados. O que não se deve admitir, no entanto, é que a adoção de uma análise pragmática afaste os fundamentos das normas ambientais.

Toda interpretação deve buscar a mens legis, ou seja, o "espírito da lei”, sua razão de ser. As normas ambientais, assim como todas as demais, foram criadas com um objetivo que não pode ser esquecido. A análise dos requisitos para a aferição do cumprimento da função socioambiental da propriedade não pode se resumir à análise de critérios práticos. A interpretação da norma deve ocorrer não pela simples literalidade, mas com o objetivo de salvaguardar os valores protegidos. Também nesse sentido o art. $5^{\circ}$ da Lei de Introdução às Normas do Direito Brasileiro: "Na aplicação da lei, o juiz atenderá aos fins sociais a que ela se dirige e às exigências do bem comum.”

Dessa forma, a interpretação das normas que explicitam a função socioambiental da propriedade deve ser realizada de forma a obter o resultado mais benéfico ao meio ambiente e à sociedade, buscando sempre o equilíbrio ambiental e o bem comum. Tal análise não pode se resumir a critérios pragmáticos, sob pena de se afastar as especificidades de cada região do país ou de cada forma de exploração ou até mesmo de cada cultura. Ao tratar de função socioambiental não há como se afastar de critério subjetivos, adaptáveis ás mais diversas realidades sociais e ambientais.

\section{CONCLUSÃO}

Dos estudos realizados, pode-se concluir que a função socioambiental atualmente se apresenta basicamente sob três aspectos: econômico (produtividade), social (bem-estar dos proprietários e trabalhadores e direitos trabalhistas) e ambiental (utilização adequada dos recursos naturais e preservação do meio ambiente). Não basta que a propriedade seja produtiva. Ela também deve cumprir os demais requisitos impostos pela lei, sob pena de desapropriação para fins de reforma agrária.

Percebe-se também que a função socioambiental da propriedade, apesar de não ser novidade no ordenamento jurídico ainda é pouco utilizada nos casos concretos. Além disso, 
nas hipóteses em que é usada, geralmente se restringe à análise de produtividade, deixando de lados os demais requisitos impostos por lei para a verificação do cumprimento da função social.

Um dos motivos para a inaplicabilidade das previsões legais se verifica no fato de que o conceito de produtividade envolve conceitos amplos e complexos, exigindo do órgão competente uma análise detalhada e muitas vezes subjetiva, o que abre várias possibilidades de discussões judiciais movidas pelos proprietários em face das decisões baseadas em relatórios do INCRA.

Para que as normas se tornem efetivas, devem conter conceitos claros e precisos, de fácil verificação nos casos concretos, sob pena de se ter uma legislação avançada, mas de difícil aplicação prática, em razão da complexidade das disposições legais e subjetividade dos conceitos aplicados.

Porém é importante verificar que a busca pela efetividade não pode levar ao afastamento dos fundamentos jurídicos e sociais das normas. Especialmente na seara ambiental, onde o objetivo é proteger direitos difusos e intergeracionais, não é possível ficar restrito a uma análise pragmática dos requisitos da função socioambiental.

A busca por critérios objetivos, que implicam no uso de tabelas e fórmulas matemáticas pode acabar por reduzir a abrangência das normas ambientais. O que se deve objetivar não é a mera verificação de adequação a índices matemáticos legais, mas sim a preservação do equilíbrio ambiental e das necessidades sociais.

$\mathrm{O}$ atual aparato legal estabelecido para a aferição do cumprimento da função socioambiental da propriedade apresenta algum obstáculos:

a) As normas estabelecidas são de difícil cumprimento, uma vez que apresentam várias definições legais e agrárias (GUT, GEE, formas de exploração da terra, Reserva legal, dentre outras) o que, não raro, torna a tarefa de verificação dos índices de produtividade uma tarefa complexa e que envolve conhecimentos de diversas áreas do conhecimento;

b) Algumas expressões existentes na lei apresentam forte subjetivismo, como por exemplo: "exploração racional" e "bem estar dos proprietários e trabalhadores", o que pode gerar interpretações diversas e longas disputas judiciais; 
c) A forma de explicitação dos requisitos pode levar a uma visão excessivamente pragmática, que não considera a "intenção da lei", o que acaba por afastar da análise dos operadores do direito, as particularidades de casa caso concreto.

Assim, conclui-se que mais do que buscar uma análise pragmática, uma "fórmula matemática" de aferição do cumprimento da função socioambiental da propriedade, o importante é buscar formas de dar efetividade ás normas existentes. O meio ambiente é essencialmente complexo, e constituídos de vários aspectos (naturais, artificiais, culturais e trabalhistas) não sendo possível a sua redução a uma equação simples e de fácil resolução.

\section{REFERÊNCIAS}

BRASIL. Instituto Nacional de Colonização e Reforma Agrária. Procuradoria Federal especializada junto ao INCRA. Lei 8629/93 comentada por procuradores federais : uma contribuição da PFE/INCRA para o fortalecimento da reforma agrária e do direito agrário autônomo / Instituto Nacional de Colonização e Reforma Agrária, Procuradoria Federal Especializada junto ao INCRA. - Brasília : INCRA, 2011.

COULANGES, Fustel. A cidade Antiga. São Paulo: Martin Claret. 2013

DWORKIN, Ronald. O império do direito. $2^{\mathrm{a}}$ Ed. São Paulo: Editora Martins Fontes, 2007. FIGUEIREDO, Guilherme José Purvin de. A propriedade no Direito Ambiental. $4^{\mathrm{a}}$ ed. Ver., atual. E ampl. São Paulo: Editora Revista dos Tribunais, 2010.

FAZIO, Federico Leandro de. La "filosofia positiva", El derecho y lãs relaciones laborales em Argentina a principio del siglo XX. Revista de Estudos Jurídicos, n. 22, 2011. Disponível em: file:///E:/Download/Dialnet-LaFilosofiaPositivaElDerechoYLasRelacionesLaborale3807241.pdf. Acesso em: 28 mar 2014

MOTA, Marcel Moraes. Posner, Kelsen e Hayek: Pragmatismo Jurídico, Positivismo Normativista e Liberalismo Político-Econômico Austríaco. Disponível em: www.publicadireito.com.br/conpedi/manaus/arquivos/Anais/sao_paulo/2208.pdf. Acesso em 07 abr 2014

MOTA, Maurício. Fundamentos Teóricos da Função Social da propriedade: a propriedade em Tomás de Aquino. Revista Aquinate, n. 9. 2009. Disponível em http://www.aquinate.net/revista/edicao_atual/Artigos/09/Artigo\%206\%20-\%20Mota.pdf.

Acesso em 03 abr 2014

NONES, Nelson. Direito de propriedade e função social: evolução histórico-jurídica. Revista Jurídica - CCJ/FURB. Vol. 13, jan/jul/2009. Disponível em http://proxy.furb.br/ojs/index.php/juridica/article/view/1602/1070. Acesso em 30 mar 2014 
PINTO JÚNIOR, Joaquim Modesto, FARIAS, Valdez Adriani. Função Social da propriedade: dimensões ambiental e trabalhista. Brasilia: Núcleo de Estudos Agrários e desenvolvimento Rural, 2005

PEREIRA,Caio Mário da Silva. Instituições de Direito Civil. Volume III. Rio de Janeiro: Forense. 2003

ROCHA, Carmém Lúcia Antunes. O princípio Constitucional da Função Social da Propriedade. Revista latino-americana de estudos constitucionais. Vol.3. Editora Del Rey. 2004.

ROSENVALD, Nelson. FARIAS, Cristiano Chaves de. Direitos Reais. $6^{\mathbf{a}}$ edição, Rio de janeiro: Ed. Lúmen Juris, 2009.

SURGIK, Aloísio. A luta pela propriedade da terra na história de Roma e no Brasil considerações críticas. , in Revista da Faculdade de Direito da UFPR, v. 32, 1999. Disponível em http://ojs.c3sl.ufpr.br/ojs2/index.php/direito/article/view/1873/1568). Acesso em 31 mar 2014 